\title{
PENGAMALAN NILAI-NILAI PANCASILA BAGI GENERASI MILENIAL
}

\author{
Devi Anggraini' ${ }^{1}$, Fauzal Fathari ${ }^{2}$, Jordi Wahyu Anggara ${ }^{3}$, \\ Muhammad Devon Ardi Al Amin 4 \\ ${ }^{1}$ Fakultas Ilmu Administrasi, Universitas Islam Malang \\ korespondensi email: devianggrini17@gmail.com \\ ${ }^{2}$ Fakultas Ilmu Administrasi, Universitas Islam Malang \\ email: ffathari@gmail.com \\ ${ }^{3}$ Fakultas Ilmu Administrasi, Universitas Islam Malang \\ email: aybe.kenzu@gmail.com \\ ${ }^{4}$ Fakultas Ilmu Administrasi, Universitas Islam Malang \\ email: mdevonardi24@gmail.com
}

\begin{abstract}
This writing is motivated by the attitude that is seen about the appreciation of the values of Pancasila which began to dissapear. Writing is based on today's life where people, especially millenials, began to shift the life guidelines from Pancasila. The results seen in the current life environment, shifts in the application of Pancasila values have long occurred and gradually increasingly alarming in line with the progress of science and technology. Individual attitudes are more visible than social with others. But there are also some who still socialize with others through joint discussions in a forum. The purpose of writing this scientific journal is to re-apply the values contained in Pancasila in the current millenial life.
\end{abstract}

Keyword: application; pancasila; millenial period; technological development.

\begin{abstract}
ABSTRAK
Penulisan ini dilatarbelakangi oleh sikap yang terlihat tentang penghayatan nilai-nilai Pancasila yang mulai hilang. Penulisan dilakukan berdasarkan kehidupan saat ini dimana masyarakat khususnya zaman millenial mulai menggeser pedoman hidup dari Pancasila. Hasil yang terlihat di lingkungan kehidupan saat ini, pergeseran dalam penerapan nilai-nilai Pancasila sudah lama terjadi dan sedikit demi sedikit semakin memprihatinkan sejalan dengan kemajuan IPTEK. Sikap individual lebih banyak terlihat dibandingkan sosial dengan orang lain. Namun ada juga beberapa yang masih bersosial dengan orang lain melalui diskusi bersama dalam sebuah forum. Tujuan penulisan jurnal ilmiah ini adalah guna menerapkan kembali nilai-nilai yang terkandung dalam Pancasila di kehidupan masa millenial saat ini.
\end{abstract}

Kata Kunci: penerapan; pancasila; masa millenial; perkembangan teknologi.

\section{PENDAHULUAN}

Setelah Indonesia menyatakan kemerdekaan, melepaskan diri dari penjajahan, bangsa Indonesia masih harus berjuang mempertahankan kemerdekaan karena ternyata penjajah belum mengakui kemerdekaan dan belum ikhlas melepaskan Indonesia sebagai wilayah jajahannya. Oleh karena itu, periode pasca kemerdekaan Indonesia tahun 1945, sampai saat ini bangsa Indonesia telah berusaha mengisi perjuangan mempertahankan 
kemerdekaan memalui berbagai cara, baik perjuangan fisik maupun diplomatis. Perjuangan mencapai kemerdekaan dari penjajah telah selesai, namun tantangan untuk menjaga dan mempertahankan kemerdekaan yang hakiki belumlah selesai. Oleh karena itu, diperlukan adanya proses pendidikan dan pembelajaran bagi warga negara yang dapat memelihara semangat perjuangan kemerdekaan, rasa kebangsaan, dan cinta tanah air (Priyambodo, 2017).

Saat ini nilai-nilai Pancasila dalam diri bangsa Indonesia mulai luntur seiring perjalanan waktu (Fitri Anggriani, 2018). Contoh kecilnya pada konsep nilai sila ke-3 yang mengajarkan persatuan, tetapi saat ini orang-orang menjauhkan nilai persatuan dan lebih hidup individual dengan menikmati perkembangan teknologi saat ini. Salah satu yang mendominasi perubahan sikap dan sifat bangsa Indonesia adalah berkembangnya IPTEK yang kian modern di Indonesia. Saat ini IPTEK mulai berkembang pesat di Indonesia, seiring zamannya yang mulai masuk revolusi industri 4.0. pengembangan IPTEK tidak terlepas dengan nilai-nilai budaya dan agama, dimana itu dapat menurunkan moral bangsa. Budaya-budaya luar mulai masuk dan menyebarluas di masyarakatnya. Sehingga berbagai macam pengaruh mulai dari internal maupun eksternal masuk ke dalam diri bangsa Indonesia. Dengan adanya Pancasila sebagai ideologi diharap mampu memperteguh sikap dan sifat masyarakat dalam menerima hal-hal diluar batas norma yang ada di Indonesia (M. Taufik, 2018).

Pendidikan Pancasila patut diajarkan lagi khususnya kepada masyarakat umum yang hidup di zaman saat ini. Banyak yang tidak dapat menerapkan nilai-nilai Pancasila pada aspek kehidupannya, karena sudah tercampur dengan budaya-budaya barat yang serba instan. Jiwa sosial antar satu dengan yang lain dalam jarak dekat kian menipis, tergantikan dengan adanya teknologi baru dimana mereka lebih mementingkan kehidupan di dunia maya (Yudistira, 2016).

Pancasila merupakan sebuah ideologi kokoh di Indonesia dimana apapun aktivitas kehidupan masyarakat berpedoman kepada Pancasila, terutama saat berhubungan dengan antar manusia yang yang berbeda-beda suku, ras, dan agama (Bhagaskoro, Utungga Pasopati, \& Syarifuddin, 2019). Maka dari itu, Pancasila mampu menjadi alat pemersatu bangsa Indonesia dan sumber nilai dalam kehidupan bermasyarakat, berbangsa dan bernegara (Shofa, 2016). Tak hanya itu saja, Pancasila juga bisa menjadi dasar moral atau norma dan tolak ukur tentang baik dan buruk, benar dan salah sikap, perbuatan dan tingkah laku bangsa Indonesia.

Pancasila yang berkembang pada situasi dunia diliputi oleh berbagai tajam konflik ideologi (Fathorrahman, 2018). Saat itu kondisi politik dan keamanan negara diliputi kekacauan dan budaya Indonesia yang sudah mulai luntur dengan adanya jajahan dari luar. Hingga terjadi pembagian masa orde di Indonesia. Pertama masa Orde Lama dengan 3 periode, 1945-1950, 1950-1959, dan 1959-1965 yang dipimpin presiden Soekarno. Kedua muncul masa Orde Baru dengan kepemimpinan presiden Soeharto. Dan terakhir masa Reformasi dimana akan diatur ulang aturan-aturan yang tidak sesuai dengan Indonesia.

\section{TINJAUAN PUSTAKA}

Pancasila adalah landasan dari segala sesuatu yang dilakukan bangsa dan menjadi ideologi bagi bangsa Indonesia. Pancasila menjadi pemersatu bangsa yang beraneka ragam suku, ras, agama dari Sabang sampai Merauke. Perkembangan Pancasila ini dimulai dari masa kerajaan hingga saat ini Indonesia sudah merdeka. Istilah Pancasila sudah dikenal sejak zaman kerajaan Sriwijaya dan Majapahit dimana aspek nilai sila-silanya sudah diterapkan di kehidupan masyarakat maupun kerajaan, meskipun belum dirumuskan secara konkrit (Darmawan, 2018). 
Ada tiga tataran nilai dalam ideologi Pancasila yaitu nilai dasar, nilai instrumental, dan nilai praksis (Agus, 2016). Ketiga nilai tersebut dijelaskan sebagai berikut:

1. Nilai dasar, suatu nilai yang bersifat abstrak dan tetap, yang terlepas dari pengaruh perubahan waktu. Nilai dasar merupakan prinsip, yang bersifat abstrak dan umum, tidak terikat waktu dan tempat. Nilai dasar Pancasila tumbuh baik dari sejarah perjuangan bangsa Indonesia melawan penjajah yang sudah menyengsarakan rakyat Indonesia, disamping cita-cita bangsa yang ditindas penjajah.

2. Nilai instrumental, nilai yang bersifat kontekstual. Nilai instrumental merupakan penjabaran dari nilai Pancasila, yang merupakan arah kinerja untuk kurun waktu tertentu dan kondisi tertentu. Nilai instrumental dapat disesuaikan dengan tuntutan zaman. Namun nilai instrumen harus mengacu pada nilai dasar yang dijabarkan. Dari kandungan nilainya, nilai isntrumental merupakan kebijaksanaan, strategi, organisasi, sistem, rencana, program, bahkan proyek-proyek yang menindaklanjuti nilai dasar tersebut. Lembaga negara yang berwenang menyusun nilai instrumental adalah MPR, Presiden, dan DPR.

3. Nilai praksis, nilai yang terdapat dalam kehidupan sehari-hari. Berupa cara bagaimana rakyat Indonesia mengamalkan nilai Pancasila. Nilai praksis banyak wujud penerapan nilai-nilai Pancasila, baik tertulis maupun tidak tertulis; baik dari cabang eksekutif, legislatif, yudikatif; oleh organisasi kemasyarakatan, badan ekonomi, pimpinan kemasyarakatan, bahkan oleh warganegara perseorangan.

Maka dari itu upaya menumbuhkan sikap diri berlandaskan Pancasila harus diterapkan sejak dini. Lingkungan keluarga maupun sekolah harus menjadi pendukung menumbuhkan sikap Pancasila. Hal kecil yang dapat dilakukan dengan mudah yaitu membiasakan rasa tolong menolong kepada yang lain dan membiasakan menyapa ketika bertemu orang lain. Karena kebiasaan kecil akan berdampak terus menerus jika dilakukan. Dengan sikap seperti itu tentunya rasa sosial akan semakin terlihat. Kemudian tekunkan ibadah, dimana kita berpikir bahwa hidup kita singkat sehingga harus ingat pada tuhan. Dan masih banyak lagi yang bisa dilakukan dari dini.

\section{METODE}

Metode penelitian adalah cara ilmiah yang dilakukan untuk mendapatkan data dengan tujuan tertentu (Anwar Hidayat, 2017). Metode yang digunakan adalah metode studi kepustakaan, dimana teknik pengumpulan data dengan mengadakan penelaahan terhadap buku-buku, literatur, catatan, jurnal yang ada kaitannya dengan masalah yang dibahas (Mirzaqon, 2018). Dimana data yang didapat dari berbagai sumber dicatat untuk memperkuat landasan teori penelitian.

Objek dalam jurnal ini adalah menurunnya pengamalan nilai-nilai Pancasila pada generasi milenial. Sedangkan subjeknya adalah masyarakat umum yang tergolong milenial dan beberapa mahasiswa Unisma. Jenis data yang digunakan dalam penelitian ini adalah data sekunder yang diperoleh dari berbagai sumber yang ada untuk mendukung pengamatan. Datanya berupa laporan, jurnal yang terkait dengan materi yang dibahas yaitu pengamalan dan isi nilai-nilai Pancasila.

\section{HASIL DAN PEMBAHASAN}

\section{Perilaku Masyarakat Milenial}

Penulis melakukan pengamatan di beberapa daerah seperti lingkungan kampus Unisma, organisasi di Kota Batu, cafe-cafe tempat nongkrong masyarakat atau mahasiswa di sekitar Dinoyo Malang. Dalam pengamatan yang dilakukan penulis, sikap yang terlihat pada beberapa masyarakat dan mahasiswa memperlihatkan sikap-sikap 
yang sudah tidak menerapkan nilai Pancasila pada kehidupan sehari-hari. Diantaranya sebagai berikut:

a. Pada sila pertama tertera "Ketuhanan Yang Maha Esa". Ketika pengamatan, masih banyak sekali masyarakat dan kalangan mahasiswa yang tidak menjalankan kewajiban beribadah sebagai umat yang beragama. Saat adzan Dzuhur berkumandang masih banyak orang yang tetap di lokasi nongkrong bahkan sampai adzan ashar berkumandang, sangat jelas orang tersebut memang berniat meninggalkan kewajiban beribadahnya. Tak hanya itu, di daerah Kota Batu dan Malang juga terdapat beberapa golongan Islam yang terbentuk dan memecah belah.

b. Pada sila kedua tertera "Kemanusiaan Yang Adil dan Beradab". Ketika berkumpul bersama dalam satu tempat memperlihatkan individual. Dimana masing-masing hanya terfokus pada gadget yang mereka miliki. Meskipun ada teman disampingnya mereka tetap saja memainkan gadget seperti tidak memedulikan orang sekitarnya. Kemudian juga sering terjadi, suatu kelompok yang tidak membela yang benar justru membela yang salah karena teman kelompoknya yang terlibat melakukan kesalahan.

c. Pada sila ketiga tertera "Persatuan Indonesia". Pada pertengahan 2019, terjadi ricuh mahasiswa Papua di Malang yang menuntut kemerdekaan bagi Papua. Yang mana seharusnya hal tersebut bisa dilakukan baik-baik mendatangi pemerintahan tidak dengan melakukan aksi ricuh di daerah bukan tempatnya.

d. Pada sila keempat tertera "Kerakyatan Yang Dipimpin Oleh Hikmat Kebijaksanaan Dalam Permusyawaratan Perwakilan". Sikap yang telihat yaitu tidak menghargai pendapat orang lain ketika berdiskusi karena menganggap pendapatnya yang benar dan pendapat orang lain tidak sesuai, menolak hadir saat diundang rapat oleh organisasi, memaksa pilihan orang lain dalam pemilihan umum.

e. Pada sila kelima tertera "Keadilan Sosial Bagi Seluruh Rakyat Indonesia". Untuk sila ini, sangat banyak sikap yang terlihat tidak diterapkan. Yaitu sikap pilih kasih dalam pergaulan masyarakat, yang mana saling berkelompok dan memilih dalam berteman. Kemudian rasa gotong royong yang semakin lama memudar, melanggar aturan lalu lintas, kelompok yang merusak fasilitas umum, membuang sampah sembarangan, melakukan tindak korupsi uang dan tidak mau bekerja sama ketika ada teman membutuhkan bantuan.

Dari kelima sila yang sudah dipaparkan diatas, terlihat jelas sikap yang dilakukan masyarakat dalam kehidupan sehari-hari tidak menerapkan nilai-nilai Pancasila yang sudah ditegakkan di Indonesia. Maka dari itu, perlulah dilakukan penanaman kembali nilai Pancasila pada generasi milenial.

\section{Pengamalan Nilai-Nilai Pancasila}

Pancasila adalah dasar falsafah negara Indonesia dan ideologi negara yang diharapkan menjadi pandangan hidup bangsa Indonesia, sehingga dasar pemersatu, lambang persatuan dan kesatuan serta bagian pertahanan bangsa dan negara. Nilai Pancasila dasarnya adalah nilai-nilai filsafat yang mendasar yang dijadikan aturan dan dasar dari norma-norma yang berlaku dalam Indonesia. Hal tersebut berarti bahwa semua peraturan yang ada dan berlaku di Indonesia harus bersumber Pancasila.

Pancasila yang berisi seperangkat nilai-nilai dasar ideal, merupakan komitmen kebangsaan, identitas bangsa dan menjadi dasar pembangunan karakter keindonesiaan. Mendasarkan pada perspektif teori fungsionalisme struktural, sebuah negara bangsa yang majemuk seperti Indonesia membutuhkan nilai bersama yang 
dapat dijadikan nilai pengikat integrasi (integrative value), titik temu (common denominator), jati diri bangsa (national identity) dan sekaligus nilai yang dianggap baik untuk diwujudkan (ideal value) (Kariyadi \& Suprapto, 2017).

Pancasila dicetuskan oleh para pendiri bangsa Indonesia agar kita mempunyai fondasi yang kuat dalam menjalankan pemerintahan. Artinya, dengan adanya Pancasila maka Indonesia memiliki dasar atau fondasi dalam bernegara sehingga tidak mudah dipengaruhi dan dijajah bangsa lain.

Pancasila sebagai ideologi nasional mempunyai wewenang dan fungsi utama yaitu sebagai cita-cita atau tujuan yang harus dicapai secara bersama-sama, yang kedua sebagai pemersatu bangsa sehingga dapat dijadikan solusi dalam konflik, dalam pernyataan fungsi ideologi tujuan suatu masyarakat adalah untuk mencapai tujuan dari ideologi itu sendiri. Ada beberapa tokoh yang mengemukakan pendapatnya tentang Pancasila yaitu Ir. Soekarno, Muh. Yamin, dan Notonegoro.

a. Ir. Soekarno

Pancasila adalah isi dalam jiwa bangsa Indonesia yang turun-temurun lamanya terpendam bisu oleh kebudayaan barat. Dengan demikian, Pancasila tidak saja falsafah negara, tetapi lebih luas lagi, yakni falsafah bangsa Indonesia.

b. Muh. Yamin

Pancasila berasal dari kata panca yang berarti "lima" dan sila berarti "sendi, atas, dasar atau peraturan tingkah laku yang penting serta baik". Dengan demikian Pancasila merupakan lima dasar yang berisi pedoman atau aturan tingkah laku yang penting dan baik.

c. Notonegoro

Pancasila adalah dasar falsafah dari negara Indonesia, sehingga dapat diambil kesimpulan bahwasanya Pancasila adalah dasar falsafah serta ideologi negara yang dapat diharapkan menjadi pandangan hidup bangsa Indonesia sebagai dasar kesatuan.

Dari tokoh-tokoh nasional itu, seharusnya kita sebagai generasi penerus bangsa mampu menerapkan nilai Pancasila dalam kehidupan kita. Patutnya kita menghargai jasa-jasa pahlawan yang sudah berhasil merumuskan dasar negara guna sebagai pedoman hidup kita. Perjuangan demi memerdekakan Indonesia melalui jalan rintangan yang berat. Namun para tokoh pahlawan Indonesia tetap pantang menyerah.

Dari sejarah yang ada, tidak hanya pemimpin nasional yang ikut mengeluarkan aspirasinya, tokoh-tokoh pemuka agama pun ikut andil dalam perumusan pancasila. Salah satunya dari kader Nahdlatul Ulama dan Muhammadiyah. Meskipun kebanyakan dari tokoh Islam, namun tetap Pancasila akan menopang dan mengakomodir berbagai suku, ras, agama yang berbeda-beda di Indonesia.

Jika balik lagi memperhatikan proses penyusunan dasar negara berupa Pancasila dan UUD 1945, itulah misi yang dibawa oleh para pemimpin rakyat agar dasar negara merupakan pondasi kokoh yang mengakomodasi kemerdekaan seluruh anak bangsa, bukan hanya Islam yang merupakan umat mayoritas.

Seiring perkembangan IPTEK yang kian maju dan modern yang masuk ke Indonesia mengakibatkan lunturnya nilai nasionalisme dan patriotisme khususnya kalangan muda zaman millenial ini. Jiwa-jiwa nilai Pancasila pun luntur yang akan menyebabkan hal buruk bagi bangsa dan negara. Maka dari itu, pendidikan Pancasila harus diinternalisasaikan ke dalam mata kuliah perguruan tinggi, guna memperdalam pengetahuan mahasiswa mengenai makna Pancasila. Tapi tidak hanya untuk perguruan tinggi saja, untuk jenjang sekolah pun juga harus ditetapkan. 
Maka dari itu perlu diadakan tentang penegasan dan mengembalikan kedudukan Pancasila sebagai dasar negara, dan ini merupakan hal yang sangat penting karena sudah terlalu banyak terjadi kesalahan penafsiran tentang Pancasila sebagai dasar negara. Dan penafsiran itu menyatakan bahwa Pancasila bukan hanya sebagai dasar negara tetapi Pancasila sebagai alat kekuasaan yang dapat mengendalikan semua apapun yang dilakukan negara Indonesia. Sebagai nilai yang bersifat abstrak, Pancasila harus bersifat konkrit dan upaya agar menjadi konkrit adalah dengan menjadikan nilai-nilai dasar Pancasila sebagai norma dasar dan sumber normatif bagi penyusunan hukum negara Indonesia yang positif bagi negara.

Menerapkan Pancasila dalam kehidupan dan perilaku sehari-hari, salah satu kedudukan Pancasila bagi bangsa Indonesia adalah sebagai pandangan hidup berbangsa. Yakni mengandung pengertian bahwa nilai-nilai Pancasila merupakan pegangan dalam mengatur sikap dan tingkah laku yang menjadi pedoman. Bangsa Indonesia harus menghayati dan mengamalkan nilai-nilai kebenarannya. Jika tidak diamalkan maka pandangan hidup tersebut tidak bermanfaat sama sekali dalam kehidupan sehari-hari. Dalam keadaan tersebut, bangsa Indonesia akan mudah dimanfaatkan pihak-pihak tertentu sehingga terjadi perpecahan.

Menurut Rajasa (2007), generasi muda harus mengembangkan karakter nasionalisme melalui tiga proses yaitu:

a. Pembangun Karakter (character builder) yaitu generasi muda berperan membangun karakter positifr bangasa melalui kemauan keras, untuk menjunjung nilai-nilai moral serta menginternalisasikannya pada kehidupan nyata.

b. Pemberdaya Karakter (character enabler), generasi muda menjadi role model dari pengembangan karakter bangsa yang positif, dengan berinisiatif membangun kesadaran kolektif denhgan kohesivitas tinggi, misalnya menyerukan penyelesaian konflik.

c. Perekayasa karakter (character engineer) yaitu generasi muda berperan dan berprestasi dalam ilmu pengetahuan dan kebudayaan, serta terlibat dalam proses pembelajaran dalam pengembangan karakter positif banmgsa sesuai dengan perkembangan zaman (Ginting, 2017).

Maka dari itu, lima butir yang terdapat di Pancasila dapat diterapkan dengan cara:

a. Memiliki satu agama dan menjalankan peribadatan dari agama yang diikuti dengan ketakwaan pada tuhan serta tidak memaksa seseorang untuk masuk ke agama yang diyakini karena setiap orang memiliki hak untuk memilih agama sesuai yang dikehendaki.

b. Menghargai perbedaan di tengah masyarakat yang terdiri dari banyaknya suku, agama, ras. Serta menjaga adab dan kesopanan, budi pekerti di dalam berbagai kondisi.

c. Cinta pada tanah air untuk menjaga persatuan dan kesatuan di tengah masyarakat karena menyadari bahwa kita bertanah air satu, Indonesia serta meningkatkan kreativitas karya yang kita hasilkan.

d. Mengawasi dan memberikan saran terhadap jalannya penyelenggaraan kedaulatan rakyat yang dilakukan pemerintah dan mengutamakan pengambilan keputusan dengan musyawarah mufakat untuk menyelesaikan suatu permasalahan, baik kepentingan dua orang atau lebih.

e. Senantiasa berusaha membantu orang lain yang dilanda kesusahan, menghormati hasil musyawarah sekalipun bertentangan dengan pendapat kita, serta berani memeperjuangkan keadilan baik untuk diri sendiri maupun untuk orang lain. 
Nilai-nilai luhur Pancasila dari dulu hingga sekarang tidak pernah berubah, tetapi penerapan nilai-nilai Pancasila sudah mulai luntur, yang diakibatkan kemajuan IPTEK dan arus globalisasi. Apabila salah satu nilai Pancasila diterapkan, maka nilai sila-sila yang lain akan terlaksana juga karena antar sila satu dengan yang lain memiliki kaitan yang kuat sehingga berfungsi sebagai filter untuk menyaring pengaruh buruk dari luar agar tidak masuk kedalam kehidupan sehari-hari, khususnya generasi bangsa yang hidup di zaman millenial.

\section{KESIMPULAN}

Pancasila sebagai dasar negara mengandung makna bahwa nilai-nilai yang terkandung dalam Pancasila menjadi dasar atau pedoman masyarakat Indonesia. Nilai Pancasila dasarnya adalah nilai-nilai filsafat yang mendasar yang dijadikan aturan dan dasar dari norma-norma yang berlaku dalam Indonesia. Pada masa sekarang ini perlu diadakan tentang penegasan dan mengembalikan kedudukan Pancasila sebagai dasar negara, dan ini merupakan hal yang sangat penting karena sudah terlalu banyak tejadi kesalahan penafsiran tentang Pancasila sebagai dasar negara. Maka dari itu, sangat perlu Pendidikan Pancasila diajarkan pada jenjang sekolah maupun perguruan tinggi. Kita sebagai generasi penerus bangsa yang hidup di era millenial tentunya harus menerapkan nilai-nilai Pancasila dalam kehidupan sehari-hari, agar apa yang kita lakukan sejalan dan sesuai dengan norma yang berlaku. Dan kita tidak sampai salah arah. Dengan kita menerapkan nilai-nilai Pancasila, secara tidak langsung kita juga sudah menghargai jasajasa pahlawan yang tak kenal putus asa dalam merumuskan rancangan Pancasila dimana mereka menghadapi tantangan yang begitu besar.

\section{DAFTAR RUJUKAN}

Agus, A. A. (2016). Relevansi Pancasila Sebagai Ideologi Terbuka di Era Reformasi. Jurnal Office, 2(2), 229-238. Retrieved from http://ojs.unm.ac.id/jo/article/download/2958/1608

Anwar Hidayat. (2017). Metode Penelitian: Pengertian, Tujuan, Jenis. Stastikian.Com. Retrieved from https://www.statistikian.com/2017/02/metode-penelitianmetodologi-penelitian.html

Bhagaskoro, P., Utungga Pasopati, R., \& Syarifuddin, S. (2019). Pancasila Dalam Interaksi Kearifan Lokal Dan Ideologi Transnasional. Jurnal Inovasi Ilmu Sosial Dan Politik (JISoP), 1(2), 112-132. https://doi.org/10.33474/jisop.v1i2.4806

Darmawan. (2018). Revitalisasi Pancasila Sebagai Pedoman Hidup Bermasyarakat di Era Globalisasi. Universitas Islam Negeri Raden Intan Lampung.

Fathorrahman. (2018). Potensi Pancasila Sebagai Falsafah Dunia. Jurnal Renaissance, 3(02), 411-418. Retrieved from http://www.ejournalacademia.org/index.php/renaissance/article/view/80

Fitri Anggriani. (2018). Opini Mengenai Hilangnya Nilai Pancasila dalam Kehidupan Berbangsa dan Bernegara. Universitas Negeri Jakarta. Retrieved from https://www.researchgate.net/publication/330468779_Opini_Mengenai_Hilangnya _Nilai_Pancasila_dalam_Kehidupan_Berbangsa_dan_Bernegara

Ginting, H. (2017). Peranan Pancasila Dalam Menumbuhkan Karakter Bangsa Pada Generasi Muda. In Prosiding Seminar Nasional Tahunan Fakultas Ilmu Sosial Universitas Negeri Medan (Vol. 1, pp. 197-201). Retrieved from heryansyahginting@gmail.com

Kariyadi, D., \& Suprapto, W. (2017). Membangun Kepemimpinan Berbasis Nilai-Nilai Pancasila Dalam Perspektif Masyarakat Multikultural. Citizenship Jurnal Pancasila 
Dan Kewarganegaraan, 5(2), 86. https://doi.org/10.25273/citizenship.v5i2.1560

M. Taufik, dkk. (2018). Pendidikan Pancasila untuk Perguruan Tinggi. (S. Hayat, Ed.). Malang: Baskara Media.

Mirzaqon. (2018). Studi Kepustakaan Mengenai Landasan Teori Dan Praktik Konseling Expressive Writing Library Research of the Basic Theory and Practice of Expressive Writing Counseling. Jurnal BK UNESA, 8(1), 1-8. Retrieved from https://jurnalmahasiswa.unesa.ac.id/index.php/jurnal-bkunesa/article/view/22037

Priyambodo, A. B. (2017). Implementasi Pendidikan Karakter: Semagat Kebangsaan dan Cinta Tanah Air Pada Sekolah Berlatang Islam di Kota Pasuruan. Jurnal Sains Psikologi, 6(1), 9-15. Retrieved from https://media.neliti.com/media/publications/128733-ID-implementasipendidikan-karakter-semanga.pdf

Shofa, A. M. A. (2016). Memaknai Kembali Multikulturalisme Indonesia Dalam Bingkai Pancasila. JPK Jurnal Pancasila Dan Kewarganegaraan), 1(1), 34-40. https://doi.org/10.24269/V1.N1.2016.34-40

Yudistira. (2016). Aktualisasi \& Implementasi Nilai-Nilai Pancasila dalam Menumbuhkan Kembangkan Karakter Bangsa. In Seminar Nasional Hukum (Vol. 2, pp. 421-436). 